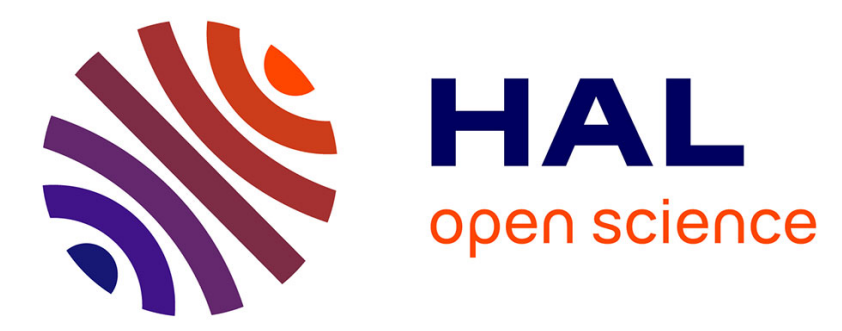

\title{
Stable and metastable orientationally disordered mixed crystals of the two-component system $(\mathrm{CH} 3)(2)$ $\mathrm{CCl} 2+\mathrm{CCl} 4$
}

\author{
Luis C. Pardo, María Barrio, Josep Lluis Tamarit, David O. Lopez, Josep \\ Salud, Philippe Négrier, Denise Mondieig
}

\section{To cite this version:}

Luis C. Pardo, María Barrio, Josep Lluis Tamarit, David O. Lopez, Josep Salud, et al.. Stable and metastable orientationally disordered mixed crystals of the two-component system (CH3)(2) CCl2+CCl4. Chemical Physics Letters, 2000, 321 (5-6), pp.438-444. 10.1016/S0009-2614(00)003687. hal-01550488

\section{HAL Id: hal-01550488 \\ https://hal.science/hal-01550488}

Submitted on 3 Jan 2018

HAL is a multi-disciplinary open access archive for the deposit and dissemination of scientific research documents, whether they are published or not. The documents may come from teaching and research institutions in France or abroad, or from public or private research centers.
L'archive ouverte pluridisciplinaire HAL, est destinée au dépôt et à la diffusion de documents scientifiques de niveau recherche, publiés ou non, émanant des établissements d'enseignement et de recherche français ou étrangers, des laboratoires publics ou privés.

\section{다(1)(2)}

Distributed under a Creative Commons Attribution - ShareAlike| 4.0 International 


\title{
Stable and metastable orientationally disordered mixed crystals of the two-component system $\left(\mathrm{CH}_{3}\right)_{2} \mathrm{CCl}_{2}+\mathrm{CCl}_{4}$
}

\author{
L.C. Pardo ${ }^{\text {a }}$, M. Barrio ${ }^{\text {a }}$, J.Ll. Tamarit ${ }^{\text {a, * }}$, D.O. López a , J. Salud ${ }^{\text {a }}$, \\ P. Negrier ${ }^{b}$, D. Mondieig ${ }^{b}$ \\ a Departament de Física i Enginyeria Nuclear, ETSEIB, Universitat Politècnica de Catalunya, Diagonal, 64708028 Barcelona, \\ Catalonia, Spain \\ ${ }^{\mathrm{b}}$ Centre de Physique Moléculaire, Optique et Hertzienne, UMR 5798 au CNRS-Université Bordeaux I, 351, cours de la Libération, \\ 33405 Talence Cedex, France
}

\begin{abstract}
Orientationally disordered stable and metastable mixed crystals of the two-component system 2,2-dichloropropane $\left(\left(\mathrm{CH}_{3}\right)_{2} \mathrm{CCl}_{2}\right)+$ carbon tetrachloride $\left(\mathrm{CCl}_{4}\right)$ have been characterised from crystallographic and thermodynamic points of view. The monotropic behaviour of the metastable phases in the pure components is retained by the mixed crystals. Continuous series of mixed crystals in the stable rhombohedral phase gives rise to an isomorphism relationship. The lattice symmetries of the metastable mixed crystals are found to be simple cubic and face centred cubic, the latter corresponding to a large concentration domain. A strong correlation between thermodynamic functions and optical properties is proposed.
\end{abstract}

\section{Introduction}

Many molecular compounds made of nearly spherical molecules exhibit at temperatures below melting an equilibrium phase characterised by a dynamic orientational disorder and by a long-range translational periodicity of the molecular centres of mass, the so-called plastic phase or orientationally disordered crystalline phase (ODIC) [1].

Methylchloromethane compounds $\left(\mathrm{CH}_{3}\right)_{4-n} \mathrm{CCl}_{n}$, ( $n$ varies from 0 to 4 ) have been studied by many groups because they are good examples of ODIC systems and, more particularly because they are the

\footnotetext{
* Corresponding author. Fax: +34-93-401-18-39; e-mail: jose.luis.tamarit@upc.es
}

only ones $(n=2,3,4)$ which display two ODIC phases with two melting points some degrees apart (about $5 \mathrm{~K}$ ) [2-11]. On cooling from the melting point, an ODIC phase Ia is formed, which, upon further cooling, transforms into another ODIC phase Ib. The orientational disorder disappears when the low-temperature ordered (LTO) phase is induced by a first-order phase transition from phase Ib. On warming the LTO phase, phase Ib is formed and remains up to the melting point. However, on heating phase Ia, it melts without reverting to phase Ib. Thus phase Ia displays a monotropic behaviour that has been extensively studied [3,4]. Birefringence measurements [5,9-11] have unambiguously shown the uniaxial character of phase Ib. Actually, X-ray diffraction measurements proved that the stable phase 
$\mathrm{Ib}$ is rhombohedral, while the metastable phase Ia displays a cubic symmetry. The orientational order in ODIC mixed crystals has been the subject of several works relating methylchloromethanes [9-11]. The 2,2-dichloropropane $(n=2)$-carbon tetrachloride $(n=4)$ phase diagram has not been studied to our knowledge, however the results of a ${ }^{1} \mathrm{H}$ NMR and birefringence work have been reported [11]. According to this work, two possible explanations of the variation of the orientational order parameters with concentration (which reduce to zero at $X=0.5$ ) deduced from several approximations (some of them being confirmed in the present work) were suggested.

This Letter reports the results of a crystallographic and thermodynamic study of the $\left(\left(\mathrm{CH}_{3}\right)_{2} \mathrm{CCl}_{2}\right)_{1-X}-\left(\mathrm{CCl}_{4}\right)_{X}$ mixed crystals. Several assumptions of the work in which the order parameters as a function of the composition were determined [11] will be confirmed and, moreover, we will discard one of the two suggested explanations. A new point of view about the correlation between the thermodynamic functions and optical properties, previously addressed [12], will be proposed.

\section{Experimental}

$\left(\mathrm{CH}_{3}\right)_{2} \mathrm{CCl}_{2}$ and $\mathrm{CCl}_{4}$ special grade were supplied by Aldrich Chemical and always handled under an $\mathrm{Ar}$ atmosphere without further purification. The transition temperatures and enthalpy changes for the pure and mixed crystals were measured with a Perkin-Elmer DSC-7 differential scanning calorimeter equipped with a home-made low-temperature device. High-pressure stainless steel pans (from Perkin-Elmer) were used in order to prevent sample reactions with the container as well as to resist the high vapour pressure of the compounds. Heating and cooling rates of $2 \mathrm{~K} \mathrm{~min} \mathrm{~min}^{-1}$ and sample masses around $25 \mathrm{mg}$ were used.

X-ray powder diffraction data were obtained by means of a horizontally mounted INEL cylindrical position-sensitive detector (CPS-120) [13] using Debye-Sherrer geometry (angular step ca. $0.03^{\circ}(2 \theta)$ ). Monochromatic $\mathrm{Cu} K \alpha_{1}(\lambda=1.54059 \AA)$ radiation was selected. The system is equipped with a liquid nitrogen INEL CRY950 cryostat that contains helium gas as a heat exchanger in the sample chamber.

External calibration using the $\mathrm{Na}_{2} \mathrm{Ca}_{3} \mathrm{Al}_{2} \mathrm{~F}_{4}$ cubic phase [14] was applied by means of cubic spline fittings. The peak positions were determined by pseudo-Voight fittings. Acquisition times were 120 min for standard measurements. Additional patterns with $180 \mathrm{~min}$ acquisition times were performed to account for the lattice symmetry of the $\left(\mathrm{CH}_{3}\right)_{2} \mathrm{CCl}_{2}$ metastable ODIC phase Ia.

The liquid samples were sealed in $0.3 \mathrm{~mm}$ diameter Lindemann capillaries which rotated perpendicularly to the X-ray beam during the experiments in order to improve the averaging of crystallites.

\section{Pure components}

According to Rudman et al., the lattice symmetry of the stable ODIC phase $\mathrm{Ib}$ of $\mathrm{CCl}_{4}$ is rhombohedral with $Z=21$ and lattice parameters $a=14.4 \AA$ and $\alpha \approx 90^{\circ}$ at $229.2 \mathrm{~K}$ [2]. Our recent work [12] has confirmed this result and accurate lattice parameters were determined to be $a=14.431$ (9) $\AA$ and $\alpha=$ $89.41(2)^{\circ}$ at $232.2 \mathrm{~K}$. The metastable Ia phase was found to display fcc symmetry with a lattice parameter $a=8.333(6) \AA$ at $230.2 \mathrm{~K}$. Transformation temperatures, $225.7 \pm 0.4,250.1 \pm 0.4$ and $245.5 \pm 0.5$ $\mathrm{K}$ for transitions II-Ib, Ib-L and Ia-L, respectively, have been determined recently [12].

Concerning 2,2-dichloropropane, the only member of the methylchloromethane series which does not have at least one three-fold molecular axis, the lattice symmetry of the stable $\mathrm{Ib}$ phase was also determined early as rhombohedral [2]; this results from the optical examination of the crystals which clearly revealed that this phase is birefringent. Morrison et al. [15] reported unambiguous birefringence measurements confirming the departure from cubic symmetry. Our results, $a=14.730(9) \AA$ and $\alpha=89.41(1)^{\circ}$ at $232.2 \mathrm{~K}$, are close to previously reported data but give more accurate values, particularly for angle $\alpha$. The metastable Ia phase has been indexed only tentatively as cubic [3]. Previous thermal measurements could not isolate phase Ia and thus determine the thermodynamic properties associated with the phase transitions. Well defined X-ray 
Table 1

Experimental $\left(d_{\mathrm{obs}}\right)$ and calculated $\left(d_{\mathrm{cal}}\right)$ lattice spacings (in Angström) for the reflections $(h k l)$ of the metastable ODIC Ia phase of $\left(\mathrm{CH}_{3}\right)_{2} \mathrm{CCl}_{2}$ at $230.2 \mathrm{~K}$

\begin{tabular}{lrlllr}
\hline$h$ & $k$ & $l$ & $d_{\text {obs }}$ & $d_{\text {cal }}$ & $d_{\text {obs }}-d_{\text {cal }}$ \\
\hline 2 & 2 & 0 & 5.1563 & 5.1547 & 0.0016 \\
0 & 0 & 3 & 4.8635 & 4.8599 & 0.0036 \\
1 & 3 & 1 & 4.3968 & 4.3959 & 0.0009 \\
2 & 2 & 2 & 4.2109 & 4.2088 & 0.0021 \\
3 & 0 & 2 & 4.0443 & 4.0437 & 0.0006 \\
3 & 0 & 4 & 2.9157 & 2.9159 & -0.0003 \\
3 & 3 & 3 & 2.8054 & 2.8059 & -0.0005 \\
4 & 4 & 1 & 2.5374 & 2.5380 & -0.0006 \\
3 & -3 & 1 & 3.3438 & 3.3448 & -0.0010 \\
4 & 0 & 0 & 3.6441 & 3.6449 & -0.0008 \\
4 & 0 & 1 & 3.5368 & 3.5361 & 0.0007 \\
4 & 1 & 1 & 3.4369 & 3.4365 & 0.0004 \\
\hline
\end{tabular}

diffraction patterns were obtained for phase Ia, which could be undercooled (by using a very slow cooling rate) down to $184 \mathrm{~K}$. The patterns were unambiguously indexed (see Table 1) by using the DICVOL91 program [16] according to a simple cubic lattice, the parameter being $a=14.639(5) \AA$ at $230.2 \mathrm{~K}$. Due to the lack of accurate density values for phase Ia, the number of molecules in the simple cubic lattice can only be estimated ( $Z=20$ or 21 ). However, if we assume that the packing coefficient of the metastable Ia phases of $n=3$ and $n=4$ methylchloromethane compounds are lower than their respective stable $\mathrm{Ib}$ phases, $Z=20$ seems to be the more likely value. Moreover, a recent study of the temperature-pressure phase diagram proves that such a value is in good agreement with the melting volume of phase Ia [17].

The measured transformation temperatures and enthalpy changes corresponding to II-Ib (187.8 \pm $0.5 \mathrm{~K}$ and $\left.6.0 \pm 0.1 \mathrm{~kJ} \mathrm{~mol}^{-1}\right)$ and to $\mathrm{Ib}-\mathrm{L}(236.6 \pm$ $0.8 \mathrm{~K}$ and $2.3 \pm 0.1 \mathrm{~kJ} \mathrm{~mol}^{-1}$ ), respectively, are close to the data in the literature [3,18]. As far as thermodynamic properties of Ia-L transition are concerned, accurate values were obtained thanks to a great number of DSC measurements because of the delicate metastability of phase Ia on warming as already mentioned in previous works [2,3]. Melting temperature and enthalpy change for phase Ia were determined to be $230.4 \pm 1.0 \mathrm{~K}$ and $1.9 \pm 0.2 \mathrm{~kJ}$ $\mathrm{mol}^{-1}$, respectively.

\section{Stable and metastable mixed crystals}

\subsection{Crystallographic study}

Fig. 1a shows the variation of the lattice parameters of the stable Ib mixed crystals as a function of concentration at $232.2 \mathrm{~K}$. Previous NMR and birefringence evidences of the uniaxial character of these crystals are now reinforced by the determination of an isomorphic relationship between the $\mathrm{Ib}$ phases of $\left(\mathrm{CH}_{3}\right)_{2} \mathrm{CCl}_{2}$ and $\mathrm{CCl}_{4}$.

In relation to the metastable Ia mixed crystals, the different lattice symmetries of such phases for the pure compounds (SC and FCC) obviously imply the existence of a demixing region. Fig. $1 \mathrm{~b}$ displays the evolution of the cubic lattice parameters for Ia phases versus concentration. As can be seen, the $[\mathrm{SC}+\mathrm{FCC}]$ coexistence region is very narrow (limiting solid solutions were only about 0.01 mole fraction apart) and completely shifted to large concentrations of 2,2-dichloropropane. Therefore, the metastable FCC mixed crystals occupy a large concentration domain with respect to the metastable SC mixed crystals.

The question of the concentration dependence of orientational order parameters [11] can now be an-

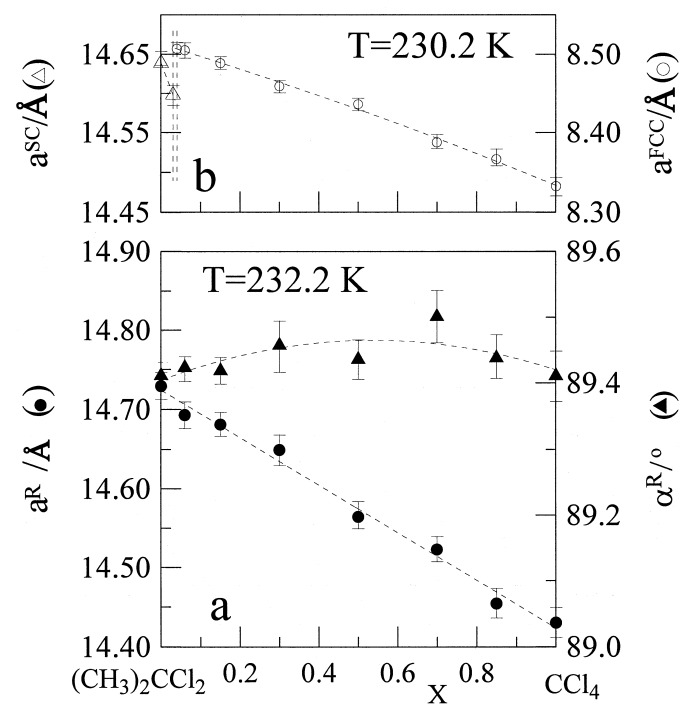

Fig. 1. (a) Lattice parameters, $a$ and $\alpha$, for the rhombohedral mixed crystals at $232.2 \mathrm{~K}$. (b) Lattice parameters of the SC ( $\Delta$, left scale) and FCC $(\bigcirc$, right scale) mixed crystals at $230.2 \mathrm{~K}$ as a function of mole fraction. 
swered. Two possible explanations for order parameters reducing to zero at equimolar concentration in the stable mixed crystals have been suggested [11]. The first one assumes that, on changing the mole fraction of the mixed crystals, angle $\alpha$ of the rhombohedral unit cell varies in such a way that $(\alpha-90)$ changes sign at $X=0.5$, corresponding to the formation of a cubic crystal. As can be seen from Fig. 1a, this is no longer possible. The second explanation, which was considered as 'hardly probable' by the authors, establishes that intermolecular interactions in mixed crystals change because of the variation of the mole fraction so that only the molecule orientations are modified, while the molecular mass centres remain at rhombohedral lattice sites and while $(\alpha-90)$ keeps the same sign in the whole concentration range. As birefringence reduces to zero at $X=0.5$, a compensation between molecular (corresponding to the molecular polarizability) and structural (anisotropy of the crystalline field) contributions to the birefringence must be assumed.

\subsection{Thermodynamic analysis}

The thermodynamic equilibria concerning ODIC phases and the liquid state have been determined from DSC measurements. Fig. 2 shows the phase diagram of the stable $[R+L]$ equilibrium together

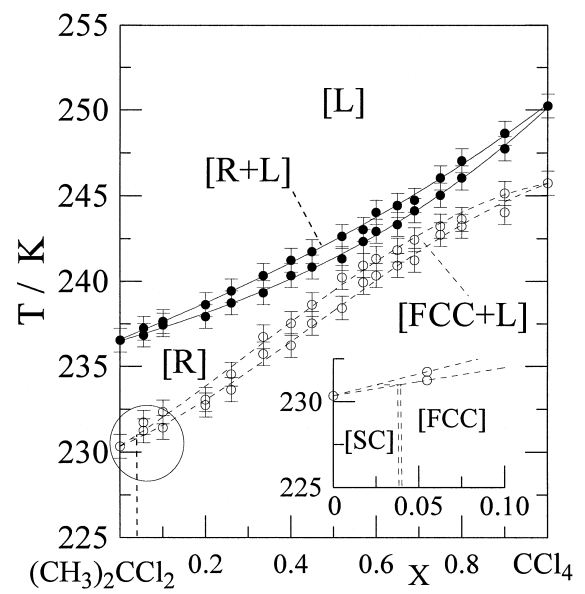

Fig. 2. Stable $[\mathrm{R}+\mathrm{L}](\mathbf{O})$ and metastable $[\mathrm{FCC}+\mathrm{L}]$ and $[\mathrm{SC}+\mathrm{L}]$ (O) melting equilibria for the two-component system $\left(\mathrm{CH}_{3}\right)_{2} \mathrm{CCl}_{2}-\mathrm{CCl}_{4}$. The inset shows the very narrow two-phase demixing domain [SC $+\mathrm{FCC}]$. with the metastable $[\mathrm{SC}+\mathrm{L}]$ and $[\mathrm{FCC}+\mathrm{L}]$ equilibria. The peritectic three-phase equilibrium line has been located at about $231 \mathrm{~K}$ according to X-ray powder diffraction measurements.

To obtain the thermodynamic properties of the stable and metastable phases and to correlate them to the measured optical properties, the excess Gibbs energy of the mixed crystals must be determined. For a continuous series of mixed crystals in phase $\alpha$, the Gibbs energy of $(1-X)$ moles of $\mathrm{A}$ and $X$ moles of $\mathrm{B}$, i.e., the mixed crystal $\mathrm{A}_{1-X} \mathrm{~B}_{X}$, can be written as:

$$
\begin{aligned}
G^{\alpha}(T, X)= & (1-X) \mu_{A}^{*, \alpha}+X \mu_{B}^{*, \alpha} \\
& +R T[(1-X) \ln (1-X)+X \ln X] \\
& +G^{E, \alpha}(T, X)
\end{aligned}
$$

where $\mu_{i}^{*, \alpha}, i=\mathrm{A}, \mathrm{B}$ represents the molar Gibbs energy of pure component $i, R$ is the gas constant and $G^{E, \alpha}(T, X)$ is the excess Gibbs energy. The two-phase equilibrium region between phases $\alpha$ and liquid (L) will be given by the intersection between their respective Gibbs energies, $G^{\alpha}(T, X)$ and $G^{\mathrm{L}}(T, X)$ at each $T$. In what follows and because of the lack of data on $\mu_{i}^{*}, j, i=\mathrm{A}, \mathrm{B}$ and $j=\alpha, \mathrm{L}$, the equal gibbs curve (EGC) method was used [19]. The differences between the Gibbs energies of phases $\alpha$ and $\mathrm{L}$ are given by:

$$
\begin{aligned}
\Delta G^{\alpha \rightarrow \mathrm{L}}(T, X)= & G^{\mathrm{L}}(T, X)-G^{\alpha}(T, X) \\
= & (1-X) \Delta \mu_{\mathrm{A}}^{*}(T)+X \Delta \mu_{\mathrm{B}}^{*}(T) \\
& +\Delta G^{\mathrm{E}}(T, X)
\end{aligned}
$$

where $\Delta \mu_{i}^{*}=\mu_{i}^{*, \mathrm{~L}}-\mu_{i}^{*, \alpha} \quad(i=\mathrm{A}, \mathrm{B})$ and $\Delta G^{\mathrm{E}}(T, X)=G^{\mathrm{E}, \mathrm{L}}(T, X)-G^{\mathrm{E}, \alpha}(T, X)$, which represents the excess Gibbs energy difference between $\mathrm{L}$ and $\alpha$ phases. Assuming that $\Delta \mu_{i}^{*}(T) \approx$ $\Delta S_{i}^{*}\left(T_{i}^{\alpha \rightarrow \mathrm{L}}-T\right)$, if $\Delta S_{i}^{*}$ is the melting entropy of phase $\alpha$, the equation $\Delta G^{\alpha \rightarrow \mathrm{L}}\left(T_{\mathrm{EGC}}, \mathrm{X}\right)=0$ provides a curve (EGC curve) where phases $\alpha$ and $\mathrm{L}$ have equal values for the Gibbs energies, which is described by the equation

$$
\begin{aligned}
T_{\mathrm{EGC}}(X)= & \frac{(1-X) \Delta H_{\mathrm{A}}^{*}+X \Delta H_{\mathrm{B}}^{*}}{(1-X) \Delta S_{\mathrm{A}}^{*}+X \Delta S_{\mathrm{B}}^{*}} \\
& +\frac{\Delta G_{\mathrm{EGC}}^{\mathrm{E}}(X)}{(1-X) \Delta S_{\mathrm{A}}^{*}+X \Delta S_{\mathrm{B}}^{*}}
\end{aligned}
$$

where $\Delta H_{i}^{*}$ is the melting enthalpy for component $i$. 
Using the experimental data at equilibrium $[\alpha+\mathrm{L}]$ (both liquidus and solidus temperatures have been used), the mathematical procedure to obtain the excess Gibbs energy difference close to the EGC curve, $\Delta G_{\mathrm{EGC}}^{\mathrm{E}}(\mathrm{X})$, is performed by means of the WINIFIT software [20] based on Oonk's method [19]. In this context, the excess Gibbs energy for a given solution is represented by a two-parameter Redlich-Kister polynomial:

$G^{\mathrm{E}, \alpha}(X)=X(1-X)\left[G_{1}+G_{2}(1-2 X)\right]$.

We did not find published excess thermodynamic functions for the liquid mixtures $\left(\mathrm{CH}_{3}\right)_{2} \mathrm{CCl}_{2}-\mathrm{CCl}_{4}$. Thus, only excess Gibbs energy differences between the ODIC phases and the liquid state can be obtained.

Relating the metastable Ia phase-liquid equilibria, non-isomorphic SC and FCC phases imply the existence of a three-phase equilibrium, which can be viewed as the result of two interfering loops, [SC $+\mathrm{L}]$ and $[\mathrm{FCC}+\mathrm{L}]$, the so-called crossed-isodimorphism (for details see Refs. [21-23]). Because of the very narrow domain occupied by the SC mixed crystals, only excess thermodynamic properties related to the FCC mixed crystals could be obtained. The extension of the $[\mathrm{FCC}+\mathrm{L}]$ loop ends $($ at $X=0$ ) at the theoretical (super)-metastable melting point of a FCC phase of $\left(\mathrm{CH}_{3}\right)_{2} \mathrm{CCl}_{2}$ which is assumed to be isomorphous with that of metastable the Ia phase of $\mathrm{CCl}_{4}$. Thanks to the large extension of the $[\mathrm{FCC}+\mathrm{L}]$ loop (see Fig. 2), its extrapolation can easily be performed, the result being close to the real SC-L phase transition of the metastable Ia phase of $\left(\mathrm{CH}_{3}\right)_{2} \mathrm{CCl}_{2}$. Thus, the thermodynamic parameters (temperature and entropy change) of this transition were used in order to calculate the excess thermodynamic properties of the FCC metastable mixed crystals.

It should be pointed out that the temperatures of $[\mathrm{R}+\mathrm{L}]$ and $[\mathrm{FCC}+\mathrm{L}]$ equilibria are close to one another; therefore, the temperature-dependence can be skipped when the hierarchy of their stabilities is compared. Calculations were performed at $240.6 \mathrm{~K}$, which corresponds to the mean value between the equimolar EGC temperatures of $[\mathrm{R}+\mathrm{L}]$ and $[\mathrm{FCC}+$ L] loops.

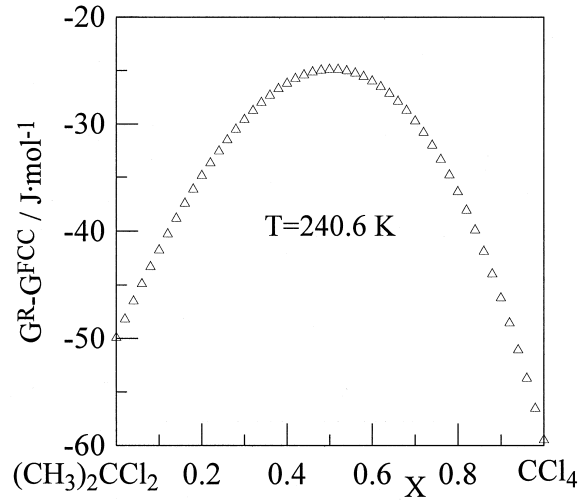

Fig. 3. Gibbs energy difference between $\mathrm{R}$ and FCC mixed crystals at $240.6 \mathrm{~K}$.

Fig. 3 displays the Gibbs energy difference between stable R and metastable FCC mixed crystals. It clearly follows that $\mathrm{R}$ mixed crystals are more stable than FCC crystals, which means that the monotropy of the FCC mixed crystals is not concentration dependent. Moreover, such a Gibbs energy difference reaches its lowest value at $X=0.5$ and then, from a thermodynamic point of view, $\mathrm{R}$ and FCC mixed crystals are more alike at equimolar composition.

In order to connect thermodynamic results with previously reported data obtained from optical birefringence measurements [11], we have used our definition of the 'excess optical birefringence', $\Delta n^{\mathrm{E}}(X)$ $=\Delta n(X)-\left[(1-X) \Delta n_{\mathrm{A}}+X \Delta n_{\mathrm{B}}\right]$, where $\Delta n_{\mathrm{A}}$ and $\Delta n_{\mathrm{B}}$ are the optical birefringence of components $\mathrm{A}$ and B, respectively [12]. Such a parameter accounts for the crystalline field changes due to the mixed crystal formation, assuming that the second contribution to the birefringence (the molecular polarizability) is roughly the same in FCC and R mixed crystals. In a similar way, the excess Gibbs energy difference between R and FCC mixed crystals must account for the anisotropy of the crystalline field (steric contributions are assumed to be equal). Thus, both parameters should have similar concentration dependences. Fig. 4 shows the excess Gibbs energy of the R mixed crystals referred to the excess Gibbs energy of isotropic FCC mixed crystals together with the 'excess optical birefringence' for the $\left(\mathrm{CH}_{3}\right) \mathrm{CCl}_{3}-\mathrm{CCl}_{4}[9,10]$ and $\left(\mathrm{CH}_{3}\right)_{2} \mathrm{CCl}_{2}-\mathrm{CCl}_{4}[11]$ 


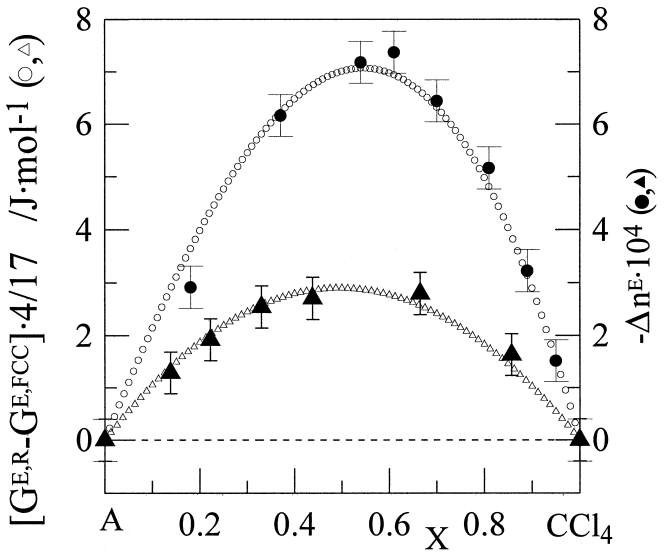

Fig. 4. Excess Gibbs energy of the R mixed crystals with respect to the excess Gibbs energy of the cubic (FCC) mixed crystals (empty symbols) and 'excess' optical birefringence (full symbols) calculated from Ref. [11] and Refs. [9,10] for the two-component systems $\left(\mathrm{CH}_{3}\right)_{2} \mathrm{CCl}_{2}-\mathrm{CCl}_{4}$ (circles) and $\left(\mathrm{CH}_{3}\right) \mathrm{CCl}_{3}-\mathrm{CCl}_{4}$ (triangles), respectively.

two-component systems. As can be inferred from this figure, concentration dependence is very similar in both cases. Moreover, it should be emphasised that a factor of $4 / 17$ is surprisingly the same for both systems (see the identical scales for both vertical axes). This unexpected result means that thermodynamic functions and the birefringence parameter can be obtained from one another in the methylchloromethane compounds.

\section{Conclusions}

The isomorphic relationship between the ODIC $\mathrm{Ib}$ stable phases of the two compounds $\left(\mathrm{CH}_{3}\right)_{2} \mathrm{CCl}_{2}$ and $\mathrm{CCl}_{4}$ has been established. On the contrary, ODIC Ia metastable phases have been found to be non-isostructural phases. Particularly, it has been shown that the lattice symmetry of phase Ia of $\left(\mathrm{CH}_{3}\right)_{2} \mathrm{CCl}_{2}$ is simple cubic. Such a structural difference between the metastable phases gives rise to a (metastable) two-phase (SC and FCC) region. In addition, it may be stressed that the width of this region is very small, a result which would indicate the similarity of the both phases in spite of the symmetry difference.
Rhombohedral Ib mixed crystals are formed in the whole concentration range. Angle $\alpha$ characterising the lattice symmetry remains lower than $90^{\circ}$ whatever the composition is. This in turn means that the zero values of the order parameters at equimolar composition must be related only to a continuous change of the intermolecular interactions in the mixed crystals. Although at mole fraction 0.5 of $\mathrm{CCl}_{4}$ stable $\mathrm{Ib}$ phase remains rhombohedral with $\alpha \neq 90^{\circ}$, the thermodynamic analysis gives clear proof of the thermodynamic 'closeness' between R and FCC mixed crystals at that composition.

Finally, we clearly established a strong correlation between thermodynamic functions and optical birefringence for the $\left(\mathrm{CH}_{3}\right) \mathrm{CCl}_{3}-\mathrm{CCl}_{4}$ and $\left(\mathrm{CH}_{3}\right)_{2} \mathrm{CCl}_{2}-\mathrm{CCl}_{4}$ binary systems which are the only ones relating methylchloromethane compounds studied until now.

\section{Acknowledgements}

This work has been supported by the Spanish DGE under Grant PB95-0032.

\section{References}

[1] N.G. Parsonage, L.A.K. Stavely, Disorder in Crystals, Clarendon, Oxford, 1978.

[2] R. Rudman, B. Post, Mol. Cryst. 5 (1968) 95.

[3] R. Rudman, Mol. Cryst. Liq. Cryst. 6 (1970) 427.

[4] L. Silver, R. Rudman, J. Phys. Chem. 74 (1970) 3134.

[5] Y. Koga, J.A. Morrison, J. Chem. Phys. 62 (1975) 3359.

[6] A. Anderson, B.H. Torrie, W.S. Tse, Chem. Phys. Lett. 61 (1979) 119.

[7] M. Djabourov, C. Levy-Manneheim, J. LeBlond, P. Papon, J. Chem. Phys. 66 (1977) 5748.

[8] J. Zuk, H. Kiefte, M.J. Clouler, J. Chem. Phys. 95 (1991) 1950.

[9] A.V. Struts, O.F. Bezrukov, Chem. Phys. Lett. 232 (1995) 181.

[10] A.V. Struts, Phys. Rev. B 51 (1995) 5673.

[11] M.N. Akimov, O.F. Bezrukov, O.V. Chikunov, A.V. Struts, J. Chem. Phys. 95 (1991) 22.

[12] L.C. Pardo, M. Barrio, J.L.I. Tamarit, D.O. López, J. Salud, P. Negrier, D. Mondieig, Chem. Phys. Lett. 308 (1999) 204

[13] J. Ballon, V. Comparat, J. Pouxe, Nucl. Instrum. Methods 217 (1983) 213.

[14] M. Evain, P. Deniard, A. Jouanneaux, R. Brec, J. Appl. Cryst. 26 (1993) 563. 
[15] J.A. Morrison, E.L. Richards, M. Sakon, Mol. Cryst. Liq. Cryst. 43 (1977) 59.

[16] D. Louër, A. Boultif, DICvOL91 program, Laboratoire de Cristallochimie, Univ. de Rennes I, France, 1991.

[17] A. Würflinger, L.C. Pardo, private communication.

[18] J.C. van Miltenburg, J. Chem. Thermodynamics 4 (1972) 773.

[19] H.A.J. Oonk, Phase Theory, Elsevier, Amsterdam, 1981.
[20] R. López, D.O. López, WINIFIT Computer Program, Polytechnical University of Catalonia, Barcelona, 1998.

[21] J. Salud, D.O. López, M. Barrio, J.Ll. Tamarit, P. Negrier, Y. Haget, J. Solid State Chem. 133 (1997) 536.

[22] J. van Braak, D.O. López, J. Salud, J.Ll. Tamarit, M.H.G. Jacobs, H.A.J. Oonk, J. Cryst. Growth 180 (1997) 315.

[23] D.O. López, J. van Braak, J.Ll. Tamarit, H.A.J. Oonk, Calphad 19 (1995) 37. 